\title{
CONGENITAL INTERRUPTION OF THE AORTIC ARCH
}

\author{
BY \\ MARGARET SEWART, B.Sc., M.B., B.Ch., D.C.H. \\ Late House Physician, Premature Baby Unit, Sorrento Maternity Home, Birmingham
}

The following case appears to be of sufficient rarity to warrant recording.

Mrs. B., aged 41 years, was delivered of her third child at home at $8 \mathrm{a} . \mathrm{m}$. On July 23, 1946. The two previous pregnancies, in 1937 and 1940, had terminated normally at full term. Maternal health in this pregnancy was good. Delivery was by the vertex. The baby was in a state of blue asphyxia at birth, but responded well to resuscitation. Immediately after delivery the child was transferred to the City of Birmingham Premature Baby Ward, Sorrento Maternity Home, under the care of Dr. V. Mary Crosse.

Clinical findings. Examination on admission on July 23,1946 , showed a female premature baby of thirty-four weeks' gestation. Birth weight was $3 \mathrm{lb} .12 \mathrm{oz}$. The length (vertex to sole) was 17 in. The colour of the skin was good. Nothing abnormal was noticed in the cardiovascular system, but there was poor air entry over the left lung-field suggesting an area of atelectasis. Next day (July 24, 1946) the baby's condition was good enough to warrant the exposure necessary for a more detailed examination. This revealed a well baby with slight generalized oedema but no cyanosis. The veins over the backs of the hands were engorged. The feet were warm. The chest was broad and shortened from above downwards. The apex-beat was visible and palpable in its normal situation. There was marked visible and palpable pulsation in the left infraclavicular (pulmonary) area. There were no murmurs but the heart sounds at the pulmonary area were abnormally loud. All other systems were normal.

A diagnosis of congenital heart disease was made on these clinical findings. At 6 p.m. that evening the rectal temperature was $101 \cdot 4^{\circ} \mathrm{F}$. The baby became dyspnoeic, and there was poor air entry with fine crepitations over the left lung. As these findings suggested an aspirative pneumonia in an atelectatic lung, penicillin therapy $(2,500$ units intramuscularly three-hourly) was instituted. During the night of July 24-25 the breathing became increasingty laboured and the pulse more rapid and forcible, until each beat could be seen through the covering blanket. The child became cyanosed and died at 7.50 a.m. on July 25, 1946, aged 45 hours 50 minutes.

Post-mortem examination. This was made on July 25, 1946, by Dr. E. C. Allibone (Birmingham Children's Hospital). The body was that of a

cyanosed baby in rigor mortis. The pericardium contained a small quantity of clear yellow fluid. The heart was normal in size. The right auricle was normal. There was a patency of the pars membranacea of the interventricular septum 4 or $5 \mathrm{~mm}$. in diameter. The first part of the pulmonary artery was normal in position and direction, and, after giving off the right and left pulmonary branches, it was continuous, without change in diameter, with an artery which in position and appearance corresponded exactly with the descending part of the thoracic aorta. The left auricle and ventricle were normal. The ascending aorta and the arch of the aorta, after giving off the innominate artery and left common carotid, terminated in the left subclavian artery. There was no communication, nor a connexion by a fibrous band, between the aortic arch and the descending thoracic aorta (fig. 1 and Plate II).

The pleurae and lungs were normal. The peritoneum contained a few ounces of clear yellow fluid. All other organs, except for a few small tentorial tears, and two lacunae in the left parietal region of the skull, were normal.

\section{Embryology}

In order to understand the nature of this deformity it is necessary to refer to the branchial aortic arches of embryonic life. The forerunners of the greater vessels consist of six aortic arches on each side. The first, second, and fifth arches on each side disappear (indicated in fig. 2 by interrupted lines). The third aortic arches persist as the common carotid arteries. The fourth right arch forms part of the right subclavian artery. The fourth left arch forms that part of the arch of the aorta between the origin of the left common carotid and the entrance of the ductus arteriosus. The dorsal part of the last right arch disappears, its ventral part forming the right pulmonary artery. The dorsal part of the last left arch remains as the ductus arteriosus, the ventral part forming the left pulmonary artery. In the neonatal period the ductus arteriosus closes and is represented in the adult by the ligamentum arteriosum. The part of the left dorsal aorta between the fourth left aortic arch and the last left arch persists as the descending part of the arch of the aorta.

In the case of Baby B. it will be seen from the above embryological note that the main defect lies 


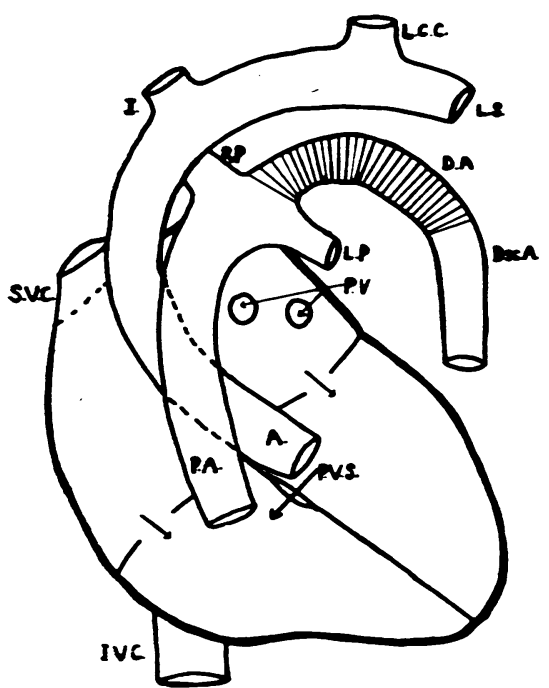

FiG. 1.-Diagrammatic representation of the abnormality

$$
\begin{aligned}
& \text { A. }=\text { aorta } \\
& \text { Dsc. A. = descending thoracic aorta } \\
& \text { D.A. = patent ductus arteriosus } \\
& \text { I.V.C. = inferior vena cava } \\
& \text { I. }=\text { innominate artery } \\
& \text { L.C.C. = left common carotid } \\
& \text { L.P. = left pulmonary artery } \\
& \text { L.S. = left subclavian artery } \\
& \text { P.A. = pulmonary artery } \\
& \text { P.V.S. = patency of interventricular septum } \\
& \text { R.P. = right pulmonary artery } \\
& \text { S.V.C. = superior vena cava } \\
& \text { P.V. = entrance of pulmonary veins }
\end{aligned}
$$

in the abnormal disappearance of the distal part of the fourth left aortic arch, and of the left dorsal aorta between the fourth and the last left aortic arches. The fourth left aortic arch is here continued as the left subclavian artery. This defect leads to an interruption in the arch of the aorta, the descending part of the arch being absent. The descending thoracic aorta becomes thus a continuation of the patent ductus arteriosus (dorsal part of last left aortic arch). This condition is really an exaggeration of the infantile form of coarctation of the aorta, the part of the vascular system which is stenosed in the latter condition being completely absent in the present case. Because of this arrangement, there is a failure of direct communication between the arch of the aorta and the descending aorta, and the whole of the blood supply to the lower half of the body consists of blood from the pulmonary artery, via the patent ductus, which, in post-embryonic life should be unoxygenated. The baby ought, therefore, to have been cyanosed in the lower half and of good colour in the upper. The only explanation for the absence of this finding appears to lie in the presence of the patent interventricular septum allowing oxygenated blood to

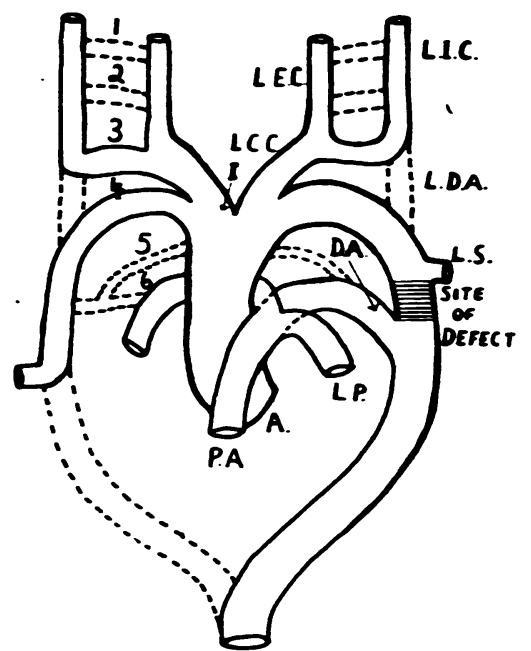

Fig. 2.-Diagrammatic representation of the aortic arches in man. The lettering has the same significance as in fig. 1, with the following additions.

$$
\begin{aligned}
& \text { L.D.A. = left dorsal aorta } \\
& \text { L.E.C. = left external carotid } \\
& \text { L.I.C. = left internal carotid }
\end{aligned}
$$

(The position of the left subclavian artery is placed as in postembryonic life after rostral migration has taken place.)

pass from the left side of the heart to the right in sufficient quantity to obscure this phenomenon.

The condition appears to be incompatible with any longer duration of life. Most reported cases died early in infancy, but one case lived to five and a half years (Maude Abbot, 1927).

There are six reported cases similar to that of Baby B. Maude Abbot (1927) collected five cases. William Evans (1933) describes one case (case 22). In none was the interventricular septum reported as having been patent.

\section{Summary}

A case of congenital interruption of the aortic arch is recorded. A short note on the embryology with reference to the pathogenesis of the condition is given. Reference is made to six reported cases.

I am indebted to Dr. V. Mary Crosse, Chief Medical Officer in Administrative Charge of City of Birmingham Maternity Homes and Premature Baby Unit, for permission to publish this case. I should also like to thank Dr. E. C. Allibone and Dr. H. S. Baar for their great help in reading and criticizing this paper, and for obtaining the photograph of the specimen.

\section{REFERENCES}

Abbot, M. D. (1927). In Osler and McCrae: Modern Medicine. London. 4, 772.

Evans, W. (1933). Quart. J. Med., n.s. 2, 16. 